

\section{Narrar as ruínas: por uma hermenêutica do conflito ${ }^{1}$}

\author{
Narrating the ruins: towards a \\ hermeneutic of the conflict
}

\section{Diego Granja do Amaral'²}

\section{DOSSIÊ}

28 PORTO ALEGRE | v. 22 | n. $38|2017|$ p. 28-42

DOl: http://dx.doi.org/10.15448/1980-3710.2017.2.29819 Sessões do Imaginário

\section{Resumo}

Lançando mão da hermenêutica em Ricoeur (2010; 2012), o presente artigo investiga a hipótese de que o território palestino como corpo político (Safatle, 2015), encontra fundamento na dimensão simbólica da palavra narrada. Com apoio do método indiciário (Ginzburg, 1989), desejamos construir esta hipótese através do rastreamento de relatos que compõem uma espécie de narrativa polifônica sobre a questão Palestina. Entre os textos estão os poemas de Mahmoud Darwish, o romance memorialístico de Sahar Hamouda, reportagens de Joe Sacco e o game Undersiege. Como operador central, a narrativa, vetor capaz de catalisar o luto em potência política. À guisa de conclusão, defendemos que a identidade palestina se organiza a partir de um mosaico de vozes a partir do exílio da memória.

\section{Palavras-chave}

Palestina; memória; narrativa.

\section{Abstract}

Using the hermeneutics in Ricoeur (2010; 2012), the present article investigates the hypothesis that the Palestinian territory as a body politic (Safatle, 2015) is based on the symbolic dimension of the word narrated. With the help of the indexing method (Ginzburg, 1989), we wish to construct this hypothesis by tracing the accounts that make up a kind of polyphonic narrative on the Palestine question. Between the texts are the poems of Mahmoud Darwish, the memorialistic romance of Sahar Hamouda, reports of Joe Sacco and the game Undersiege. As central operator, narrative, a vector capable of catalyzing mourning in political power. By way of conclusion, we argue that Palestinian identity is organized from a mosaic of voices from the exile of memory.

\section{Keywords}

Palestine; memory; narrative. 


\section{Apresentação}

No presente trabalho, discutiremos diferentes formas de emergência da memória do povo palestino em suas implicações políticas e identitárias. Com este exercício pretendemos discutir a importância dos textos produzidos a respeito daquela nação para a conformação de um corpo político posterior à criação do Estado de Israel.

Nesta medida, nossa proposta se aproxima de uma noção de identidade narrativa, como destacada em Ricoeur (2010). De forma sintomática, o exemplo trabalhado pelo autor é precisamente o povo judeu, que teria extraído sua identidade da recepção do texto bíblico, por eles produzido.

Em contraste com a identidade judaica, que em grande medida contribui para a própria constituição do ocidente moderno, assumimos como premissa a observação de Mahmoud Darwish, que vê a Palestina como metáfora. A figura de linguagem sintetizaria “ [...] a perda do Éden, as dores da despossessão e do exílio, e o declínio do poder do mundo árabe em suas negociações com o Oeste" ${ }^{{ }^{3}}$ (Shatz, 2001, tradução nossa). É tendo isto em vista que desenvolveremos nossa proposta, sempre em diálogo com as palavras de Darwish.

Isto posto, observaremos registros produzidos a partir de três pontos de vistas emblemáticos: o do indivíduo exilado, aqui representado pelo poeta Mahomoud Darwish, responsável pela declaração de independência da Palestina e poeta símbolo da nação (Shatz, 2001); o daquele que já nasceu no exílio, como Sahar Hamouda, que tenta recuperar sua história a partir de relatos da mãe a respeito da casa da família no território ocupado de Jerusalém oriental; e por fim, o do estrangeiro, com Joe Sacco, cujas reportagens acerca do território palestino dão voz a uma pluralidade de pontos de vista orquestrados pelo cronista.
Com esta triangulação, desejamos traçar um panorama sobre diferentes tentativas de esculpir um espaço simbólico que se entenda como Palestina. Em outras palavras, buscamos narrativas que tentam costurar memórias a fim de restaurar um corpo político. Afinal, a Palestina já renasce no imaginário contemporâneo como território mutilado pela criação do Estado de Israel no ano de 1948. Com o fim do mandato britânico na região, a Palestina passa a existir como denegação: aquilo que não é Israel. Ou Jordânia, ou mar.

O gesto político maior é a ruptura pela criação. É pela plasticidade diante do abismo da contingência que a política configura novas práticas, novos modos de ser e fazer ver. No caso da Palestina, pela memória se inventa para resignificar ruínas e ausências. Inspirados em Safatle (2015), reconhecemos que a todo corpo político é marcado não apenas por relações materiais de trocas, mas também por um circuito de afetos, como sugere o título mais recente do autor.

Ao compreender as relações políticas como contendo em sua natureza as trocas afetivas, abrimos espaço para as manifestações invisíveis aos olhos. É nesta seara que damos vazão ao pensamento sobre a memória enquanto força política que tensiona os registros oficiais. Como lembra Ricoeur (2007), é dever da memória fazer justiça a uma história criminosa.

Acionando a faculdade das lembranças, pessoais ou coletivas, é possível recusar uma história que se recusa a reconhecer o real. Logo, é legítimo afirmar também que, a despeito de acusações sobre a baixa confiabilidade histórica de relatos memorialísticos, como é o caso dos que citaremos neste trabalho, argumentamos que sua principal qualidade é precisamente recusar a objetividade construída pela episteme oficial em favor da percepção individual do relato. Afinal, como veremos adiante, em se tratando de um Estado-Nação não reconhecido pela história ou pela geografia, é preciso reformular os narrares para dar voz aos que não existem na ordem oficial. Pois é precisamente na distribuição da palavra que reside a atividade política (Rancière, 2010).

No caso sobre o qual nos debruçamos, o luto é um afeto central do processo de simbolização. Afinal, concordando com Mbembe (2006), entendemos necessário reconhecer a Palestina como emblema das práticas da necropolítica contemporânea, onde o poder de impérios coloniais legisla sobre uma quantidade massiva de vidas. De forma particularmente cruel, o necropoder se faz presente naquela região não apenas retirando vidas, mas cerceando o direito ao luto, como que provocando uma morte simbólica pelo silenciamento das vozes.

É nesta medida em que a verbalização da memória contribui para o estabelecimento de novas formas políticas e a reconfiguração do corpo que se compreende como Palestina.A cada novo relato, soma-se um ponto de cor à costura de um tecido opaco, quase invisível, porque silencioso.

À guisa de método, iremos atentar para casos que, embora dispersos no tempo e espaço, se ligam por um fio comum: um exercício que funciona como tentativa de construir um lugar a partir da ausência. Em outras palavras, o empreendimento de reconstruir uma identidade Palestina para além das fronteiras geográficas e a partir dos escombros de um conflito que progressivamente desconstrói um território. E neste processo, pensamos que a questão que aqui se dirige à Palestina se refere, em espectro ampliado, à plasticidade de todo corpo que luta contra a norma. 
Isto posto, discutiremos a hipótese de que a identidade palestina encontra como último esteio a palavra. Palavra aqui entendida como linguagem e que "é também uma ação [...] a partir dela algo que não existia passa a existir" (Lacan, 2005, p. 31). Ou seja, um povo que, como qualquer outro, existe ao narrar a si mesmo. E neste caso em particular, um povo que resiste à medida que é narrado. Ainda que pelas vozes de outrem, como é o caso das reportagens de Sacco (2016) a que iremos nos referir.

Recorrendo a escritas de outrem, aqueles que atravessam a rua ou observam da calçada, nos apoiamos no paradigma indiciário (Ginzburg, 1989) para compor nossa investigação de uma estética do conflito. Estética aqui entendida como exercício político da redistribuição do sensível (Rancière, 2010).

Tal escolha metodológica não é casual. Afinal, o modelo indiciário se caracteriza como ponto de convergência entre a história da arte, em Morelli, a psicanálise freudiana e a literatura de Arthur Conan Doyle (Ginzburg, 1989). Em comum, este modelo que encontra fundamento na semiótica médica, visa a compreensão de um cenário complexo a partir de seus indícios. É por este caminho que desejamos desenvolver um debate que procura aproximações entre a literatura, a psicanálise e a estética como instrumentos para a instituição de novas formas políticas na ordem simbólica.

Doravante, inspirados na medicina, onde este raciocínio permite a verificação de doenças a partir de seus sintomas, procuramos reconhecer a figura da $\mathrm{Pa}$ lestina como corpo político a partir dos rastros deixados pelos autores que falam e narram aquele lugar e suas memórias. E, por conseguinte, reconhecer na forma da palavra escrita a emergência da memória presente na oralidade das vozes narradas.
Trazer à tona os relatos, e justapô-los em mosaico, permite contemplar os fragmentos distribuídos na forma de memórias, experiências e ruínas arquitetônicas como parte de um todo, cujo processo de construção se dá na medida em que se enxergam as relações entre essas partes. Naturalmente, não é ambição deste trabaIho legar uma conclusão absoluta para o problema colocado na hipótese. O questionamento que nos motiva é encarado como ponto de inflexão para a costura de um gesto que se some a tantos outros que procuram tatear a presença deste situado entre os muros da oralidade e do documento, da legislação internacional e do direito de um povo a seus afetos.

\section{A necessidade de narrar, ou Palestina como corpo político}

Palestina é um termo que pode igualmente definir um Estado nacional que ocupa a posição de membro observador na Organização das Nações Unidas (ONU) ou uma designação sem território correspondente, como prefere o governo americano que, entre outros, não reconhece o Estado palestino.

Em um recente capítulo da celeuma, a multinacional Google, responsável pelo maior serviço de geolocalização do planeta, foi acusada de remover a Palestina do mapa. Segundo manchete do jornal britânico The Guardian, a questão é "um pouco mais complicada" (Cresci, 2016). Conforme explicará a matéria, o Google nunca teria reconhecido o termo Palestina e um erro no programa (bug) teria ocasionado a extinção temporária de Gaza e Cisjordânia. Ainda de acordo com o periódico, a celeuma motivou uma nota de protesto por parte do Fórum de Jornalistas Palestinos (Cresci, 2016).
A disputa entre o Fórum de Jornalistas Palestinos, parte da comunidade internacional e a empresa americana ilustram a complexidade do conflito. Por um lado, há a acusação de extinção de uma Nação. De outro, a empresa argumenta que o marcador ${ }^{4}$ Palestina nunca existiu. Posição compatível com o posicionamento do governo americano, que reconhece os territórios Gaza e Cisjordânia. A diferença de termos implica em um jogo de palavras que extingue a legitimidade da presença palestina naqueles territórios já seccionados pela criação do Estado de Israel e pelo conflito entre as nações em 1948

A despeito da defesa sugerida pela empresa americana, que aponta para um erro aparentemente trivial, o episódio é emblemático de uma violência radical: o apagamento do nome. Em primeiro plano, o não reconhecimento do termo "Palestina" por parte do Google implica, em algum nível, na recusa em admitir a existência política da Palestina. Como consequência de operações desta natureza (epistemológica), legitimam-se as ocupações do território palestino como a já citada construção de casas e rodovias exclusivas para israelenses em Jerusalém ocidental.

Não por acaso, para Said (2001), desde 1948 o povo palestino tenta reorganizar sua identidade a partir do exílio. Tomando a afirmação como ponto de partida, olharemos para a narrativa como guardiã de uma identidade nacional em constante reconstrução a partir de fragmentos da memória. Se, para Ricoeur (2012), a narrativa é responsável por organizar o tempo vivido, discutiremos aqui a narrativa como responsável por transformar a memória em ato político. Afinal, por óbvio que pareça, neste caso lembrar é recusar-se a esquecer. Em Ricoeur, a hermenêutica se desenvolve em 
termos de uma dialética entre o mundo narrado, produção do discurso e a performatividade implicada no ato da leitura.

Nesta medida, tomando a Palestina como objeto/ sujeito de nossa fala, reconhecemos nas dimensões citadas por Ricoeur eixos para a articulação de nosso pensamento. Com efeito, naquela região observa-se: um território em constante mutação ${ }^{5}$ de ordem urbanística e geopolítica; corpos que resistem, ainda quando desabrigados, exilados e mutilados física e/ou moralmente, que produzem sentido sobre o lugar e se conformam em ruínas formando a paisagem de uma nação radicalmente heterotópica6; leitores dentro e fora das fronteiras do país que procuram compreender um conflito complexo a partir de lentes fragmentadas.

Tendo em vista tais condições, guiamos nossa análise através das três instâncias de formação do sentido na narrativa propostas por Ricoeur (2012): o mundo pré-configurado, ou mundo do autor, onde encontramos o território em sua dimensão concreta; o mundo configurado, instância que se refere ao relato feito pelo autor na composição da intriga, neste caso da narrativa histórica; e, finalmente, o mundo reconfigurado, onde atua o leitor. Em nosso exercício, as três camadas se encontram entrelaçadas na análise, conforme os tópicos que seguem.

a) O território, a ruína como vestígio. Aqui temos como referência um espaço marcado pelo conflito bélico que se desenha na forma de tanques israelenses que ocupam ruas, barricadas, estradas exclusivas para judeus que ocupam territórios palestinos, habitações financiadas pelo Estado de Israel em território palestino, casas perfuradas por balas e desocupadas de forma que os telhados fossem ocupados por militares (Sacco, 2016).

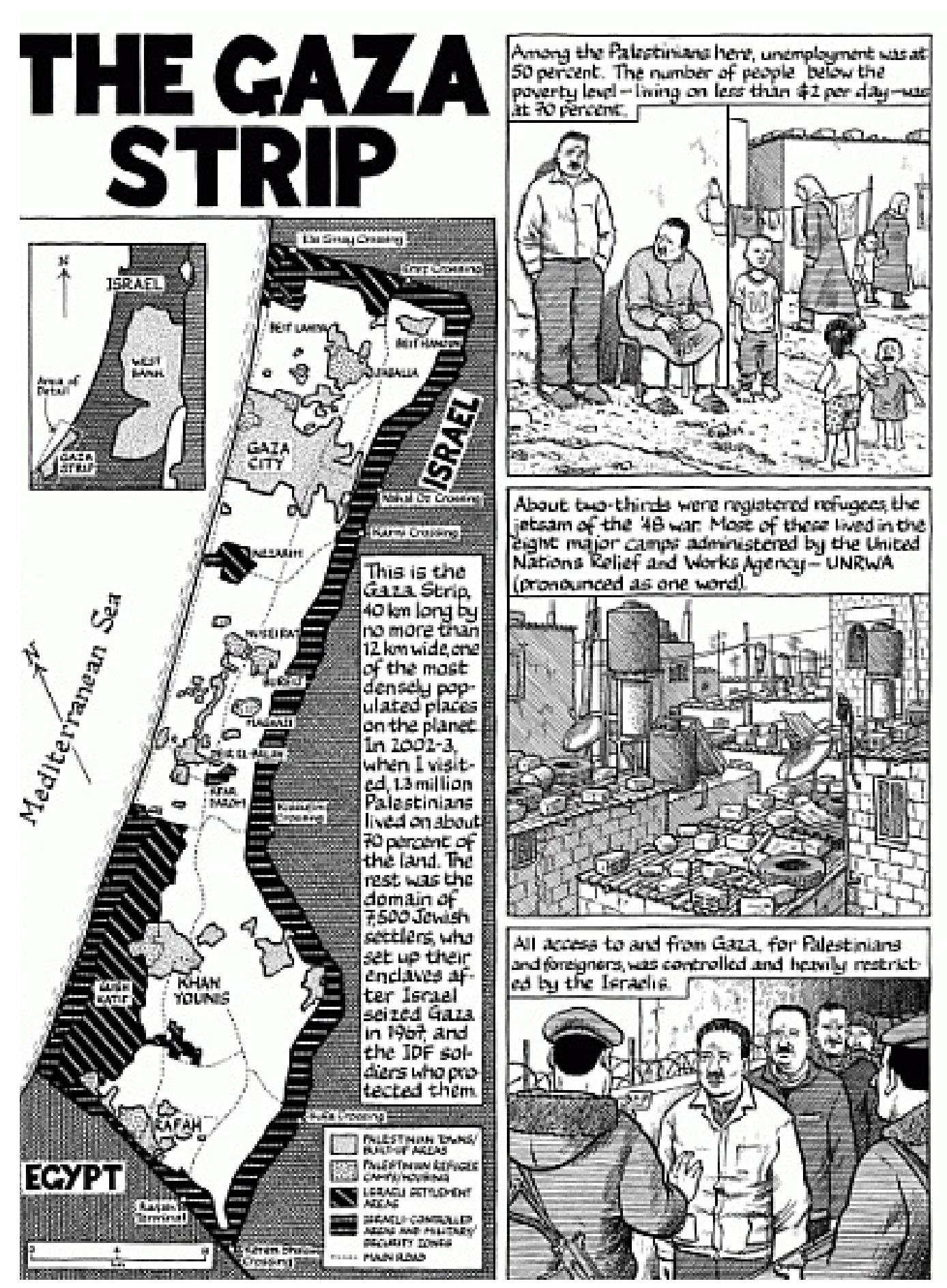

Figura 1.

Fonte: Sacco (2010). 
b) A palavra, a ruína como metáfora. Refletindo sobre a melancolia despertada pela visão de ruínas de monumentos históricos, Hegel afirma que o fato positivo a respeito das ruínas é justamente que elas apontam "ao mesmo tempo o surgimento de uma vida nova, de que da vida surge a morte e da morte, a vida" (Hegel 2004, p. 124). É nesse sentido que a presença das ruínas não apenas indica os vestígios de violações, mais que isto, as ruínas demandam a criação de novas formas Aqui interessa a capacidade das narrativas citadas em promover um olhar sobre tais ausências, como faz Darwish (2007; 2009).

c) O povo, a ruína como fundamento. Este é o es paço de conformação de identidades sócio-históricas Tendo em vista a proposta de uma identidade narrativa (Ricoeur, 2010) entendemos a narrativa como organizadora de identidades. Em Ricoeur (2010), é possível compreender a narrativa como um operador capaz de conferir unidade à experiência da contingência. Não por acaso o autor nega a noção de unidade como "um mesmo" eu (idem) durante toda a vida e se dirige a uma ideia de uma manutenção de si (ipse). Com efeito,

[...] a diferença entre idem e ipse não outra senão a diferença entre uma identidade substancial ou formal e a identidade narrativa. [...] Diferentemente da identidade abstrata do Mesmo, a identidade narrativa, constitutiva da ipseidade, pode incluir a mudana, a mutabilidade, na coesão de uma vida (Ricoeur, 2010, p. 419).

O relato, então, oferece ordem e forma à memória. A palavra reorganiza o território em constante mutação. É na materialidade do relato que as dores, afetos e formas sensíveis entram no circuito político. Munidos da materialidade dos filmes, fotos, reportagens, memoriais e afins, palestinos e estrangeiros podem apontar: ali está a Palestina. Isto se percebe com clareza na crônica familiar de Hamouda (2010).

Seja em sua dimensão de preservação da experiência histórica, ou na conotação política/existencial, é preciso costurar os fatos e as coisas em um quadro lógico diante de uma realidade que escapa à razão. É preciso também evocar um lugar apagado do território. Diante da geografia mutante, a estabilidade se faz na forma como se vê e diz o espaço.

Assim, nos referimos à palavra como lugar. Isto com o intuito de apontar em direção ao espaço simbólico, em constante elaboração, que reúne as condições para uma luta pela soberania. E assim sendo, nos alinhamos a Heidegger, no entendimento de que lugar é aquilo

que reúne e recolhe para si. O recolhimento percorre tudo e em tudo prevalece. Reunindo e recolhendo, o lugar desenvolve e preserva o que envolve, não como uma cápsula isolada mas atravessando com seu brilho e sua luz tudo o que recolhe de maneira a somente assim entregá-lo à sua essência (Heidegger, 2003, p. 27).

Para Heidegger, não se trata de pensar o local como fundamento a partir do qual se parte. Ele seria, antes, aquilo que se distende, "desenvolve" abraçando o espaço e desvelando sua essência. O lugar, portanto, revela a coisa. Em nosso caso, a linguagem estabelece um novo território sobre aquele já exaurido. Adotando os termos da hermenêutica de Ricoeur (2010; 2012), na intriga reconfigura-se o mundo. Especialmente quan- do o mundo são escombros, paredes furadas por projéteis e terra revirada por tratores. Porque este também é lugar de esperanças, alegrias e histórias de outra vida. Ou ainda desta mesma vida, histórias que não aparecem no noticiário internacional.

O mundo em questão é restaurado pela palavra a partir dos fios da memória que escapam à normatividade. A memória é também lugar de extrapolação, como se percebe no trecho em que Hamouda descreve seus antepassados em Jerusalém. Ali a autora se refere à notável beleza dos homens e mulheres da família (Hamouda, 2010). E, embora narre as memórias de sua mãe, com seu olhar e afetos, a autora assume para si a hipérbole.

Ao legitimar a percepção da mãe, a escritora afirma a existência passada de homens e mulheres de beleza extraordinária e, assim, evoca sua presença nesta condição. Assim, o verbo atualiza a vida.

Embora aparentemente banal, a menção à beleza extraordinária apreende a radicalidade da construção intersubjetiva da realidade e introduz esta leitura do mundo à história escrita da família. Ao fazê-lo, o texto resgata também o afeto. Na dimensão estética da beleza e do carinho familiar, desvela-se um aspecto do passado que extrapola a palavra escrita ou as vigas da casa. Mais que reportar o passado, narrar, aqui, é um exercício de resgate do passado e de sua atualidade. que aspecto que iluminava este passado que vai além das paredes e escritura da casa. Pois é pelos belos homens e mulheres que um dia habitaram aquela casa, pelos momentos de ternura e rigor familiar que se luta. Não pela escritura, paredes ou móveis.

Lugar, portanto, não é um ponto no mapa. Um risco que pode ser apagado pela força de tanques, ou da 
tecnologia, operados pelo capital internacional. O lugar é onde a coisa encontra a si. Nesta medida, pretendemos desvelar uma noção de palavra enquanto lugar. E de narrativa como assentamento da memória.

Onde não há terreno para raízes, a ficção e o documento suspendem o espaço. Uma identidade nacional amparada pela lembrança de um povo. Vista como atualidade, a memória não é só a expressão do que foi, mas, sobretudo, incorporação do passado como elemento de coesão e atualização do corpo social.

A Palestina corporifica um embate que corta a realidade. Em uma zona em que a guerra é uma constante há mais de 50 anos, as constantes cisões operadas no mapa implicam em um apagamento de lugares e modificam a paisagem simbólica da Palestina. Por outro lado, como que em uma operação do inconsciente lacaniano, a Palestina retorna a si na forma do real. Aquilo que a geografia, física e humana, parecem não ter sido capazes de simbolizar retorna na forma de conflito. Isto é, ainda que, em diversas áreas reduzida à forma de escombros, a Palestina se vê reconstruída pela força das narrativas que retoma o espectro do que fora negado.

É isto que se vê, por exemplo, quando Faris Odeh lança uma pedra contra um tanque. De forma sintomática, o garoto palestino repete, em essência, outra imagem icônica, a do jovem sentado em frente a um tanque na China de 1989. Na analogia entre os casos é notável a potência de uma construção político-estética que parece se repetir no tempo. Ali, a imagem vibra como que recusando a opressão das forças institucionais que esmagam indivíduos.

Por outro lado, territórios afetivos e existenciais são constituídos a partir de bases nem sempre concretas. É o que sugere Mahmoud Darwish (2007) quando se refere à Palestina como miragem. Este também parece ser o caso da já citada Hamouda, que tenta recompor a história de sua família a partir de relatos orais e vestígios de registros históricos.

Admitir uma política dependente da capacidade de narrar é também reconhecer que para o Estado-Nação contemporâneo, e instituições de poder transnacional, faz-se necessária a criação de inimigos do poder. Como sugere Mbembe, em estados de exceção, ou estados de sítio, "o poder (que não é necessariamente um poder estatal) faz referência contínua e invoca a exceção, a urgência e uma noção 'ficcionalizada' do inimigo"7 (Mbembe, 2006, p. 21, tradução nossa).

No caso dos povos árabes, majoritariamente mulçumanos, e da Palestina em particular, a condição de inimigo do poder hegemônico se faz dupla. Por um lado, há a disputa por território com Estado de Israel, que remete à própria fundação deste em 1948 permanecendo até os dias atuais. Por outro lado, como aponta Said (2015), após a queda da União Soviética, o próprio Departamento de Defesa americano conduziu estudos para a escolha de um inimigo comum. Neste caso, o inimigo escolhido foi o Islã.

Tendo em vista a condição do conflito Israel Palestina como um permanente estado de exceção, ao qual pode-se acrescentar a chamada "guerra ao terror" que toma corpo em especial no Oriente Médio, a fabulação do real ocupa um espaço estratégico no cenário geopolítico. Nesta medida, assim como a contenda por zonas territoriais, o conflito demanda uma disputa talvez ainda mais profunda, a luta pela vocalização de uma imagem compartilhada e difusa sobre o território.

\section{Poética da memória}

O desafio aqui é recompor a trança do tempo. Mais especificamente, tentaremos observar de que forma, a partir de 1948, com a fundação do Estado de Israel, começa a se configurar de forma latente uma nova ideia de Palestina. Diferentemente do Estado sub judice da coroa britânica que preexistia à criação de Israel, em 1948 a Palestina passa a ser um território mutilado. Nesse sentido, como um corpo que precisa reconhecer a si mesmo diante da ausência de um ou mais membros, a fundação de Israel demanda a reconfiguração da Palestina como identidade. É preciso inventar outro corpo político para enfrentar a guerra.

Como pontapé inicial em nossa empresa de cartografar vozes que configurem o corpo político entendido como Palestina, partimos do poeta Mahmoud Darwish. Concordando com Farsakh (2009), reconhecemos em Darwish um elemento central da identidade palestina. Como defende a autora, o poeta deu voz àquela luta tanto em sua vida pessoal quanto em sua atuação política. Esta percepção se estende também, e especialmente, à obra de Darwish, que para figuras como o crítico literário Subhi Hadidi pode ser considerado, inclusive, um "[...] salvador da língua árabe" (Shatz, 2001, tradução nossa) ${ }^{8}$.

De forma emblemática, é preciso reconhecer que, neste, como em qualquer caso, não é possível estabelecer uma linha que separe instituições, eventos históricos e indivíduos, como aliás sugere o conceito de Foucault. Afinal, todos esses elementos se configuram como dispositivos que formam uma rede de relações de saber e poder responsável por formas de subjetivação e, portanto, identidades (Foucault, 1977; Deleuze, 1990).

Embora uma análise aprofundada sobre a Palestina 
demande um olhar que se volte a uma história milenar, aqui pretendemos cobrir manifestações que partem da Palestina ocupada para a elaboração de um lugar. É também naquela data que a voz de Darwish, lida por Arafat, emerge formalmente como catalizador do pensamento político na Palestina. Trata-se da carta de declaração de independência da Palestina, que ocorreu no dia 15 de novembro de 1988. No libelo, as palavras do poeta e o símbolo político representado por Arafat reúnem a imagem de uma nova nação.

Em um dos trechos da carta, destaca-se uma referência ao entrelaçamento umbilical entre uma identidade formada pelo povo árabe palestino, "sua terra e sua história" (Viva Palestina, 1988). Pois terra e história não se separam. E juntas formam o povo árabe palestino. Esta relação é particularmente importante para o reconhecimento de nossa hipótese de que, em obras como esta, também redigida por Darwish, mais que a formalização de uma vontade política, reside a tentativa de preservar a memória de um povo. Além disto, trata-se de narrar as ruínas para que elas não se transformem em pó, reinserindo-as na ordem da história. Como demonstra o caso emblemático de Jerusalém, é a história que significa a terra.

Outra passagem do texto se refere aos palestinos como tendo seus corpos feridos e lembra que este sofrimento é reforçado por declarações como a que "a Palestina é uma terra sem pessoas" (Viva Palestina, 1988). Novamente aqui a noção de ausência, neste caso pelo não reconhecimento da existência concreta e simbólica de todo um povo e, igualmente, a metáfora do corpo ferido, para tratar de uma população afetada física e moralmente.
Mais à frente, o texto irá retomar o problema da negação de uma identidade e mesmo da existência da Palestina, desta vez referindo-se nominalmente ao Estado de Israel. Ali se lê: "Agora, finalmente, a cortina caiu em torno de uma época inteira de prevaricação e negação. A intifada colocou o cerco à mente do Israel oficial, que há muito tempo confiou exclusivamente no mito e no terror para negar completamente a existência palestina" (Viva Palestina, 1988). Na noção de negação e ausência, encontramos uma marca do poeta responsável pelo texto. Profundamente marcado pela sua origem palestina e condição de expatriado, $\mathrm{Da}$ rwish têm na ausência e no desamparo dois de seus elementos centrais.

É importante salientar que, ao invés de representarem exclusivamente razões para amargura, tais afetos são frequentemente acionados como potência criativa e transformadora. Tal questão se observa, por exemplo em um trecho de uma das obras mais emblemáticas do autor. Ali, musa inspiradora e Palestina se confundem em uma construção política e afetiva. llustramos este ponto com um excerto: "Na ausência dela, eu criei sua imagem: a partir do terreno / começa o celestial oculto. Estou aqui ponderando / a vastidão com as odas Jahili ... e ausência / é o guia, é o guia" (Darwish, 2007, p. 199,

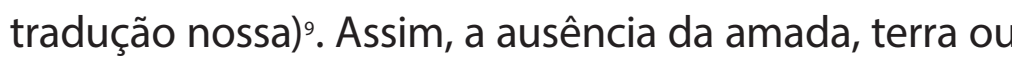
pessoa, ideia ou corpo, se reconfigura.

É precisamente a lacuna da presença que motiva e orienta o eu lírico. A Palestina, musa. Não sua presença, mas negatividade que exige a escritura. Justamente nesse espaço lacunar, motivado pela falta, que Darwish lança mão da miragem. Mais que uma utopia, a miragem é presença. É o corpo político constituído pela falta. Diferente daquele que se conforma pelas re- lações imediatas, a miragem é reflexo da condição de precariedade deste sujeito individual e político. E precisamente aí que reside sua potência.

A miragem, aliás, é uma presença constante na poesia de Darwish. Em outro momento de sua obra, a miragem é descrita como "o guia de viagem" no deserto...sem ele o viajante não continuaria marchando por água (Darwish, 2017). É ela, a esperança, que mantém o viajante vivo. Lembremos que Darwish é ele mesmo exilado e passou sua vida em diversos países sem encontrar em nenhum deles seu Éden. Nem mesmo em Gaza. Contudo, parece seguir os conselhos da própria quimera que descreve. E ela diz: "Lê, se és capaz de ler. Escrevei, se és capaz de escrever. Ele lê: áqua, áqua. E escreve uma linha na areia: se não fosse pela miragem, eu não estaria mais vivo"10 (Darwish, 2017, tradução nossa). Obediente a seus próprios fantasmas, o poeta lê, escreve e se alimenta das formas que cria na ausência de uma terra. E, oferecendo mais um indício de que é também ele o viajante a que se refere, afirma "a boa fortuna do viajante é que a esperança é gêmea do desespero, ou seu poema improvisado"11 (Darwish, 2017, tradução nossa).

Não é por acaso que justamente um poeta seja considerado um símbolo da Palestina. Ainda mais adequado que o poeta em questão seja Darwish, que prefere escrever sobre a Palestina no exílio, justamente por não reunir condições adequadas para tal em sua pátria. Segundo ele, não é possível fazer poesia no território em guerra. Talvez esta seja mais uma pista para justificar nossa composição de textos exilados. Como dirá o mesmo escritor, o problema da literatura palestina reside no fato de que "[...] nós não podemos nos livrar do momento histórico" (Shatz, 2001, tradução nossa) ${ }^{12}$. 


\section{Habitar a si mesmo, a casa}

\section{como ausência}

Se, como afirma Badiou (2009), o sujeito só pode ser concebido em relação com um lugar, a identidade palestina é, hoje, atravessada pela presença física e ideológica do conflito com Israel, particularmente nos territórios ocupados em Gaza. Não por acaso, Mbembe (2006) descreve a presença colonial palestina como o exemplo mais bem-acabado de necropoder. Segundo ele, ali "o Estado colonial baseia sua pretensão de soberania e legitimidade da autoridade em seu próprio relato da história e da identidade" (Mbembe, 2006, p. 46 , tradução nossa) ${ }^{13}$. O teórico ainda reforça que disciplinas como geografia, história e arqueologia servem ao embasamento da tese colonial.

A própria terminologia adotada para descrever o estado da invasão israelense em Gaza exige um artifício narrativo: ocupação. Não se trata de uma condição do território, como normalmente nos referimos às cidades contemporâneas. Gaza não é, está ocupada. Tão transitivamente quanto os refugiados que dependem de abrigo em um lugar qualquer que é, igualmente, lugar nenhum. Novamente a marca do tempo se exerce de modo indelével. Tudo que está precisa ser lembrado, sob pena de não ter existido. Faz-se necessária a formulação, o ordenamento daquilo que se apresenta como fluxo para que se perceba a potência política e existencial desta condição.

O espaço ocupado é aquele cuja designação aguarda no tempo. $\mathrm{O}$ termo assim esconde a perversão de um espaço que é lar para um povo. Lembrando uma das múltiplas imagens que se pode evocar desta violência, retomamos Hamouda (2010).

Na tentativa de manter vivo um lugar já não acessí- vel pelo corpo, Sahar Hamouda narra as memórias de sua mãe exilada da Palestina. Mais especificamente, $e$ de forma emblemática, o romance memorial Era uma vez em Jerusalém ${ }^{14}$ relembra as histórias da casa que pertence à família antes 1948, quando o conflito com Israel implicou no exílio de milhares de palestinos. A casa em questão é a da família Fitani, ou Dar al Fitani's, personagem central do romance.

Neste conto de fadas, baseado na própria história, a escritora descreve o momento em que sua mãe se vê com a chave de sua casa pendurada em uma corrente em torno do pescoço enquanto observa uma família vivendo em seu antigo lar. Impedida de ir até sua antiga casa, a senhora palestina, ainda em posse das chaves e documentos de sua casa, percebe seu presente que Ihe fora tomado e entregue a outra família cuja única legitimidade é ser judia.

No relato, fica evidente a necessidade de dar voz a causas e corpos, ainda que separada pelo tempo, em gerações, e pelo espaço, do território palestino. Uma tentativa de vocalizar a injustiça e minimizar a impotência de quem observa de pé que a distância entre si e seu lar é uma fronteira.

Não por acaso, ao descrever sua motivação para a escrita, Hamouda declara a tentativa de resgate de um passado histórico e afetivo de uma família e um povo injustiçados. Como dirá Hamouda,

Eu voltei no tempo e arrastei das profundezas relutantes da minha mãe, uma história que valia a pena ser contada. Há um mundo exótico de muIheres confinadas, e homens duros. Mas também há um dar de pé em um dos lugares mais sagrados do planeta. Nela houveram vidas ordinárias de ho- mens, mulheres e crianças, e de heróis e lutadores da resistência e um espaço violado e saqueado por soldados e bandidos. Ali espraiam-se minhas raízes, que remontam a tempos imemoriais. Afinal, a casa estava de pé quando Saladino retomou Jerusalém. Eu trago a voz das mulheres de Jerusalém, que foram silenciadas pela tradição, pelos homens, pela ocupa ção, e por todas as formas de opressão. Eu vou capturar a história pré 1948 desta família de Jerusalém antes que ela entre no esquecimento (Hamouda, 2010, p. 6 , grifos nossos, tradução nossa) ${ }^{16}$.

A potência do excerto revela algo além de uma carta de intenções. Em primeiro plano, a autora procura resgatar suas "raízes que remontam a tempos imemoriais", das lembranças "relutantes" de sua mãe. Em busca de fazer emergir sua própria história, a autora revela o exercício de resgatar histórias que convocam um mundo que não mais existe na matéria. Um espaço que não é apenas geográfico no sentido plano, mas que corresponde à noção de espaço proposta por Massey (2008), espaço habitado, atravessado pelo tempo das pessoas e das coisas, processual, onde se cruzam heróis e pessoas comuns, mulheres oprimidas e homens duros. Espaço vivo.

$\mathrm{O}$ verbo habitar nos persegue. Habitar é fazer-se presente no interior do mundo. Pensar a Palestina é pensar a partir dos escombros de edifícios não mais habitados fisicamente. $\mathrm{O}$ que resta então? Apoiados em Hamouda (2010), diremos: restam as palavras que convocam as coisas ao mundo. Mais especificamente, convocam um retorno dessas coisas ao mundo.

As palavras transportam o lugar através do tempo permitindo que lá habitem as pessoas. Isto não implica 
dizerquenão háolugarPalestina.Gaza, Cisjordânia,Jerusalém são memória viva e concreta, ainda que mutilada.

No encontro entre o relato registrado por Hamouda e o pensamento de Heidegger, relembramos nossa hipótese. E se o território palestino é o território narrado? Como dirá o filósofo "a linguagem fala" (Heidegger, 2003, p. 14). Ali, Heidegger marca um ponto de inflexão deste trabalho. Da afirmação se extrai que a linguagem não é "falada". Ela fala. Produz sentido em si. Esta é a importância estratégica da palavra, da narrativa, da memória palestina quando verbalizada. Não se trata do resgate de um mundo dos escombros. $O$ exercício é de produção de um mundo na palavra.

Seguindo o mesmo raciocínio, ao falar, dirá mesmo o autor, a linguagem convoca as coisas à existência. De forma sintomática, no trabalho sobre a linguagem, o filósofo busca seus fundamentos na dimensão da poiésis. Particularmente, na poesia. Da análise sobre a poesia de Trakl destacamos o seguinte comentário: "as coisas nomeadas são evocadas em seu fazer-se coisa. Fazendo-se coisa, as coisas des-dobram mundo, mundo em que as coisas perduram, sendo a cada vez a sua duração. Fazendo-se coisa, as coisas dão suporte a um mundo" (Heidegger, 2003, p. 17).

De forma similar, em Era uma vez em Jerusalém, buscamos também o exercício poético em prosa. É isto que ocorre no conto de Hamouda que, nascida no exílio, tenta recuperar um passado não vivido por ela. Além da importância do registro afetivo da história familiar, o livro traz uma contribuição a partir de um lugar de fala emblemático. Afinal, trata-se de uma mulher árabe, radicada no Egito, que escava documentos e, principalmente, as lembranças de sua mãe em busca de um passado velado. Como colocado pela escritora, a retomada não se faz sem alguma dor, sobretudo de sua mãe que compartilha suas reminiscências de forma relutante.

Para além do reencontro afetivo com o passado, a obra busca constituir uma narrativa válida dentro dos padrões canônicos. Além de suas raízes árabes, e de sua mãe exilada, é na condição de professora vinculada à faculdade de Alexandria que a autora escreve. Talvez atendendo a este aspecto de sua identidade profissional, Hamouda afirma ter buscado "fatos, imagens e datas que tristemente faltavam" à narrativa de sua mãe (Hamouda, 2010, p. 6, tradução nossa) ${ }^{17}$. Este elemento do depoimento, embora soe natural, revela o dilema de um povo cujo lugar histórico é negado pelas instituições.

Nesse processo, Era Uma vez em Jerusalém registra a dimensão pessoal de eventos históricos. Isto se nota, por exemplo, na dificuldade da autora em resgatar documentos que atestem a veracidade dos fatos e, portanto, a legitimidade documental de seu trabalho. A tentativa é frustrada, como admite a autora no trecho onde reconhece que, ela: "aspirante a historiadora, só podia lançar minhas mãos em desespero na dificuldade em obter os nomes ou datas que estavam sempre escorregando fora de meu alcance" (Hamouda, 2010, p. 58-59, grifos no original, tradução nossa) ${ }^{18}$.

Para fins desta pesquisa, convém reconhecer que os relatos não carecem de legitimidade. Afinal, não desejamos pensar o vínculo entre o que é contado e a história documental. Pelo contrário, o interesse é de traçar linhas em uma cartografia afetiva do território, a partir de múltiplas vozes e "a despeito da documentação oficial", que se faz ausente. Entendemos que esses relatos, de forma análoga à poesia de Trakl, encontram nas palavras escritas sua existência.
Antes de ser um caso isolado, a ausência de informações sobre as famílias que deixaram a Palestina após a ocupação de territórios por parte do Estado de Israel é precisamente uma das motivações declaradas por Hamouda para a escrita do livro. Segundo ela, que lecionou em uma universidade libanesa, seus alunos "não tinham um passado Palestino, apenas um presente libanês"19 (, Hamouda, 2010, p. vii-viii, tradução nossa). Fato que reforça nossa hipótese sobre a importância da palavra narrada para constituição da identidade palestina. Pois, parafraseando Hamouda, o desafio é atualizar o passado para que este seja presença hoje. Porque, ainda que evocando o passado, é presente o tempo da política

\section{Contemplar as ruínas}

Madrugada em Hebrom. Ramadã, 1994. Uma câmera aérea atravessa a cidade em direção a uma mesquita. Ouve-se as palavras suaves de uma prece coletiva. Em seguida, é possível vislumbrar um grupo de homens concentrados entoando cânticos no interior do templo.

$\mathrm{Na}$ tomada subsequente, um homem portando uma metralhadora aguarda nervosamente para, na sequência, substituir as orações por gemidos pela força de mais de 100 tiros (BBC, 1994). A cena em questão é o corte de abertura do jogo Under Siege (Afkar Media, 2005). É também uma simulação do ataque que ficou conhecida como Massacre do Túmulo dos Patriarcas.

De acordo com a rede britânica $\mathrm{BBC}$, o saldo do atentado aponta para o número de 30 muçulmanos mortos durante a rajada de projéteis que teria durado em torno de dez minutos (BBC, 1994). Além dos mortos no templo, outras 250 pessoas teriam ficado feridas, e o número de mortos pode ter alcançado os 70 , segundo reportagem da rede Al-Jazeera (Wiles, 2014). O atirador, 
que vestia um uniforme de militar israelense na reserva, foi subjugado e assassinado pelos sobreviventes.

O homem em questão, Baruch Goldstein, havia publicado anos antes uma carta explicitando seu ódio à comunidade árabe no jornal The New York Times. Segundo Goldstein "Ceder a 'Cisjordânia' aos 'Palestinos', portanto, não resolveria o problema que o rabino Hertzberg suscita: servirá apenas para pôr em perigo a segurança de Israel e trair uma confiança bíblica"20 (New York Times, 1994, tradução nossa). Destacamos as aspas presentes na citação original. Ali, Goldstein não reconhece a Faixa de Gaza e o termo palestinos. Gaza para Goldstein é "Judea" ou "Samaria".

Já os palestinos não têm nome. No artifício das aspas, se nega ao mesmo tempo lugar e a identidade dos palestinos. Assim, anos antes do ataque físico, já se fazia presente publicamente a tentativa de anular as palavras.

É notável que, em primeiro plano, o autor do massacre tenha proferido seu discurso de ódio através de um veículo como o New York Times. De forma sintomática, Goldstein aponta em sua carta para o que seria, segundo sua conclusão, a necessidade de um Estado judeu totalitário. Justaposta às cenas do massacre representado em Under Siege, a carta aparece como prenúncio de uma violência anunciada.

Anos depois, dirigindo o olhar para a vida em Hebrom, o Massacre no Túmulo dos Patriarcas aparece novamente em outro dos fragmentos de nosso corpus. Desta vez em uma reportagem de Joe Sacco, produzida por encomenda para a revista Time (Sacco, 2016). A matéria é construída na forma de desenhos acompanhados de textos que apresentam a voz do autor, entrevistados e seu olhar sobre o espaço, este último na forma de ilustrações.
Neste relato aparece um tencionamento que já nos é familiar pois repete, de certa forma, a questão colocada por Hamouda ao relatar as memórias de sua mãe. No caso de Sacco, a indagação toma a seguinte forma: "Como responder, por exemplo, quando perguntam se o desenho pode aspirar à verdade objetiva? Não é justamente da verdade objetiva que trata o jornalismo?". E continua, "desenhos, por natureza, não são subjetivos?" (Sacco, 2016, p. 1).

Novamente, o paradigma da verdade se coloca entre a representação da Palestina e o relato. Mais uma vez o relato toma os contornos da experiência através da memória, neste caso corporificada de forma gráfica, não mais na oralidade de Era uma vez em Jerusalém, de Sahar Hamouda.

Sobre as reportagens paira justamente o paradigma da objetividade, que parece demandar explicações do repórter. Reagindo a essa cobrança de um leitor ideal, o autor descreve a ênfase na neutralidade como uma "busca servil pelo equilíbrio" (Sacco, 2016, p. 3).

E assim, Sacco responde a suas próprias questões: "a resposta para a última pergunta é sim" (Sacco, 2016, p. 1), reconhecendo que seus desenhos como sendo representações inerentemente subjetivas. Em outro trecho, a resposta do autor ganha contornos que novamente merecem destaque para este debate: "o cartunista desenha tendo em mente a verdade essencial, não a literal, o que permite ampla variedade de interpretações e ampla variedade de estilos de desenho" (Sacco, 2016, p. 3-4). No excerto, dois pontos são fundamentais: o jornalista reconhece a existência de uma "verdade essencial", ainda que seja discutível a apropriação do termo como recurso retórico, é marcante a proximidade com a terminologia adotada por Heidegger.

Não percamos de vista que, o pensamento heideggeriano sobre a linguagem parte justamente de um referencial poético, e segundo o próprio, passível de interpretações que nada tem vercom vontade doautor. Nem por isto, o poema deixa de se constituir em algo essencial.

Retomando a reportagem, um quadro nos chama atenção. Nele se vê um homem sentado em uma cadeira de rodas e um quadro que traz a representação de dois homens ensanguentados sobre o chão. O homem em questão é Mohamed Abu Ilhalaweh, descrito nos seguintes termos que sucedem seu nome: "pai de quatro, estava na mesquita do Haram al-Khalil quando o Dr. Baruch Goldstein, do assentamento de Kiryat Arba, entrou e matou 29 muçulmanos durante o culto" (Sacco, 2016, p. 17). No mesmo quadro, o personagem que lamenta: "as baixas do passado não são mais lembradas. Ninguém se preocupa conosco porque sempre há mais baixas, mais vítimas, e mais de 30 mártires até o momento, só nesta Intifada" (Sacco, 2016, p. 17, grifos nossos). Goldstein, contudo, é lembrado. Inclusive, no relato acima, na condição de doutor, referência à sua profissão nos Estados Unidos.

Na composição disposta em tirinhas, o massacre não é destacado como evento particular, é paisagem. E como tal a história ganha força, pois Sacco compõe um quadro de sua caminhada pelas ruas de Hebrom. $\mathrm{O}$ estilo cartunesco permite a mescla de depoimentos, retratos e imagens. A estratégia permite ao artista ilustrar suas percepções em dimensões não lineares. 


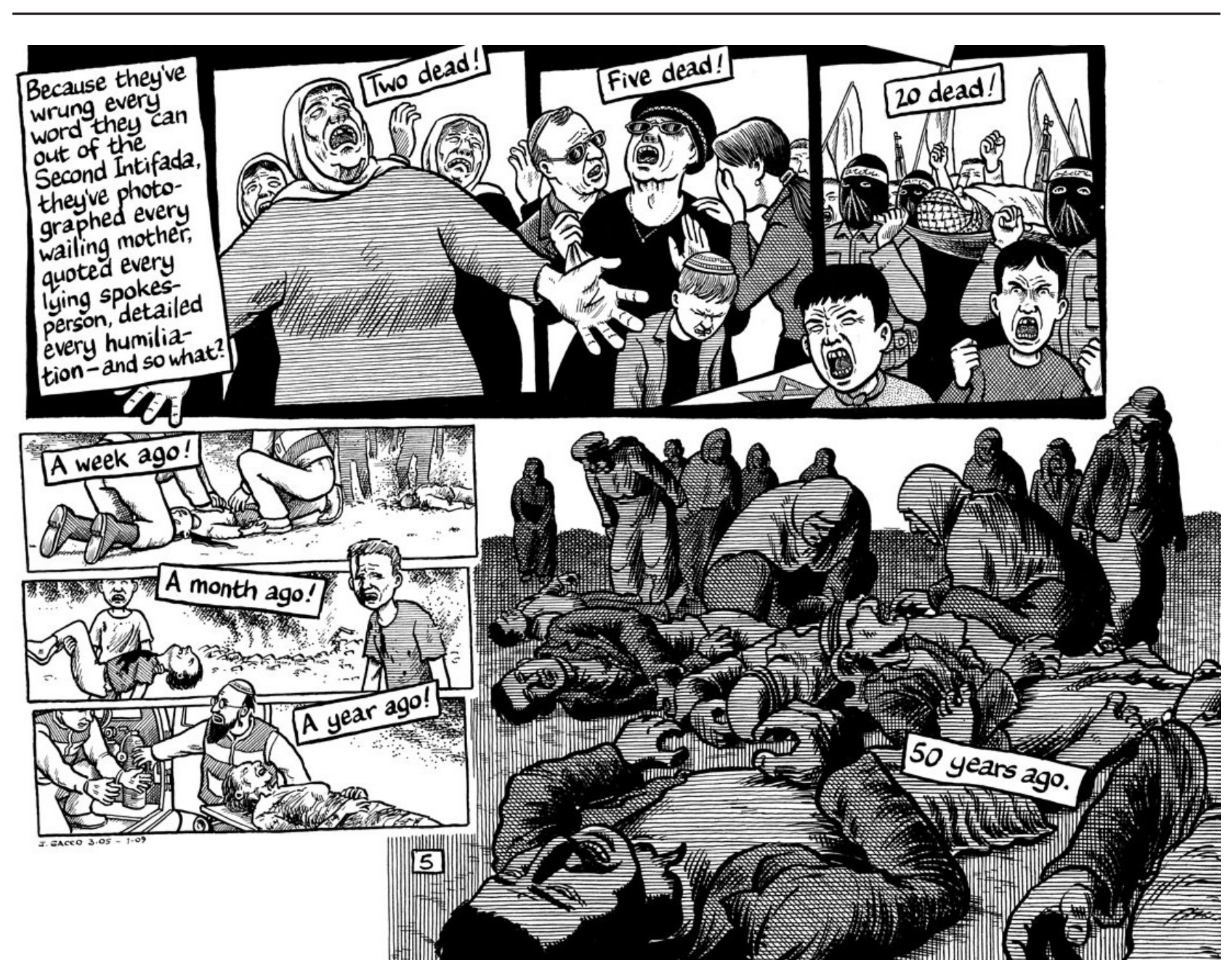

Figura 2.

Fonte: Sacco (2010)

É na justaposição dos quadros que se ligam os rastros. Na relação ganha força a articulação entre o sujeito mutilado, o quadro emoldurado lembrando o massacre que mescla violência étnica e religiosa, e a banalidade do cotidiano marcada pela visita e pelo bate-papo. Não há registro de uma denúncia, apenas a constatação da violência que atravessa a rotina com a naturalidade de um transeunte que depende da autorização de soldados estrangeiros para circular em sua cidade.

Nas reportagens que compõem o capítulo organizados sob o título de "Territórios palestinos", é possível reconhecer o olhar estranho do americano vagando através de casas marcadas por buracos de cartuchos de balas. Entre escombros, o autorvislumbra um conflito en- tre coisas e pessoas. A narrativa se inicia na barricada armada para dificultar o trânsito dos palestinos, passa pelo mapa da região dividido entre territórios controlados pelos palestinos e israelenses, até a casa de Abu llhalaweh.

Entre as falas fica evidente, por parte dos palestinos, a alternância entre a melancolia oprimida e a necessidade de contar como forma de resistência. Bem como as pedras atiradas contra tanques, as palavras dirigidas ao jornalista têm pouco efeito. Mas é preciso lançá-las ao mundo. A insurgência não reside no efeito material, mas na importância simbólica do gesto de sublevação.

É na materialidade do conflito, marcado pelas ausências provocadas pela violência que o jornalista encontra a Palestina. Em Hebrom, o corpo mutilado de llhalaweh, a foto na parede que guarda cadáveres jogados no chão, a parede marcada pelos projéteis. Em Gaza, a paisagem dá lugar a barcos de pesca abandonados por pescadores removidos, ruínas e transeuntes que lutam com pedras contra uma escavadeira israelense. Contra as coisas, balas, metralhadoras, escavadeira, a presença fantasmática do inimigo é também a ameaça de um vazio que se estende. Mais que uma ocupação, no sentido de preenchimento, as reportagens revelam a despossessão provocada pelo desequilíbrio da guerra.

Pensar e fazer política a partir da precariedade parece ser, aliás, requisito fundamental para a revolução. Não por acaso, retomando uma leitura marxista de proletariado, Rancière (1995, p. 67) salienta que "em latim, proletarii significa 'pessoa prolífica' - pessoa que faz crianças, que meramente vive e reproduz sem nome, sem ser contada como fazendo parte da ordem simbólica da cidade". Exatamente por esta razão, a classe proletária é apontada por Marx como elemento transformador. 
Não por acaso, as armas mais emblemáticas na representação do lado palestino são pedras e corpos. Pedras que indicam vestígios de construções ora sagradas para um povo, uma família ou um indivíduo. Edifícios que talvez não significassem nada, tornam-se pedras no mosaico de uma memória coletiva composta pelo marcador universal da ausência. Corpos marcados que lutam com quaisquer armas inclusive, em casos minoritários, mas emblemáticos, sacrificando o próprio corpo pelo suicídio.

Outra imagem salta à lembrança: os monges em chamas que defendem o Tibete da invasão chinesa. Mais uma vez, a negação radical, a do lugar, conduz à abnegação absoluta. Assim, a nulidade alimenta as chamas do renascimento. A dor de saber o membro mutilado torna-se libelo por um novo corpo.

Retomando Rancière (2010), lembramos que a voz para os gregos, articulada politicamente distingue os homens de meros animais que gemem por prazer ou dor. No caso em questão, pela recuperação do direto à palavra se reconfiguram poéticas e estéticas de uma identidade fragmentada pela violência. Na constituição de textos que dão voz, se fazem também sujeitos políticos que ultrapassam a mera da fruição em direção ao fazer político.

\section{Considerações finais}

Desde o título, defendemos que a narração da memória coincide com o regime de resistência política. Partilhar uma história é dar a ver um ponto de vista, atribuir vozes e trazer à vida eventos. No caso da Palestina, diante da negação de um território estável, a memória é o lugar onde se constitui o território político.

Afinal, contra o povo palestino é operada a forma mais radical de violência, aquela praticada contra sua existência no imaginário coletivo. Nesta operação, através de atos de violência física contra corpos civis, o Estado de Israel, endossado por forças políticas hegemônicas, tenta o apagamento de um corpo presente: a Palestina, em matéria e memória. Por um lado, há a destruição de corpos, estradas e casas, como observa Sacco (2016). De outro, como consequência, se perdem histórias familiares (Hamouda, 2010) e, de forma mais radical, o lugar onde existir (Darwish, 2007; 2009).

Diferentemente da terra, o verbo é acessível tanto àqueles que ocupam a Faixa de Gaza, Cisjordânia e Jerusalém, quanto aos que vivem no exílio, por vezes sem sequer ter vivido na pátria originária. É na condição de recurso para a emergência de uma comunidade nacional que a palavra se transforma em instrumento político.

Em um território exaurido pela guerra, onde a espoliação de vidas flerta com a indiferença da comunidade global, o verbo devolve à terra o direito ao luto. Como Antígona, que resiste ao Estado grego ao enterrar seu irmão, a Palestina resiste ao narrar seus mortos. $O$ gesto de Antígona ao enterrar o irmão é o de não permitir seu apagamento simbólico.

Enterrar os mortos é um gesto simbólico. E, como sugere Lacan (2005), o processo de simbolização é fundamental para a configuração da realidade. No caso da Palestina, argumentamos que é precisamente a tentativa de excluir aquele território do imaginário hegemônico que marca a violência contra aquele povo. Negar a palavra, calar vozes e apagar seu registro. A ocupação de territórios na faixa de Gaza por colonos israelenses, por exemplo, mais do que deslocar famílias silenciando sua dor, caracterizam uma tentativa de sobrescrever a história de um povo naquela terra.
É também a retomada deste lugar pelo luto e pela palavra que se instaura a resistência. Não por acaso para Lacan, "o que caracteriza a espécie humana é justamente cercar o cadáver de algo que constitua uma sepultura, de sustentar o fato de que isso durou. A lápide ou qualquer outro sinal de sepultura merece exatamente o nome de 'símbolo'"' (Lacan, 2005, p. 36).

De forma emblemática, Lacan enfatiza a condição material do símbolo. A pedra que se pode tocar, que acolhe o pranto, aquela a quem o enlutado dirige o olhar. Não uma imagem na memória. É aquela pedra, o "ser-aí". A pedra. O solo. E para além da pedra e do solo, a memória do território que foi tomado, mas que existe no mundo. Ainda que, como último recurso, pela palavra.

Em um processo análogo ao exercício terapêutico, a narrativa devolve à ordem simbólica indivíduos e histórias excluídas do imaginário coletivo. O registro da memória sobre o papel resgata sua substância. Pela presença de um corpo, se distribui o tecido simbólico que confere a identidade a um povo.

Finalmente, reconhecemos que tentar vislumbrar o "lugar" Palestina é assumir uma tarefa sem conclusão. Neste esforço, procuramos lançar luz sobre uma outra compreensão de lugar, aquele onde a palavra, a memória e a identidade trançados pela narrativa assumem consequências políticas.

Certos de que o esforço nunca será suficiente, encontramos refúgio nos dizeres de Heidegger (2003, p. 28), para quem "a poesia de um poeta está sempre impronunciada. Nenhum poema isolado e nem mesmo o conjunto de seus poemas diz tudo". Um poema concreto, assim é a Palestina em sua memória presente. 


\section{Referências}

ADIOU, Alain. Theory of the Subject. Londres: A\&C Black, 2009.

BBC. 1994: Jewish settler kills 30 at holy site. Disponível em: <http://news.bbc.co.uk/onthisday/hi/dates/ stories/february/25/newsid_4167000/4167929.stm>. Acesso em: 10 fev. 2017.

CRESCI, Elena. Google Maps accused of deleting Palestine - but the truth is more complicated. The Guardian, 2016. Disponível em: <https://www.theguardian. com/technology/2016/aug/10/google-maps-accused-remove-palestine >. Acesso em: 20 jan. 2017.

DARWISH, Mahmud. A river dies of thirst. Beirute: Archipelago Books, 2009.

The Butterfly's Burden. Newcastle: Bloodaxe, 2007.

The dice Player. In: Poem Hunter. Disponível em: <https://www.poemhunter.com/poem/the-diceplayer-2/>. Acesso em: 10 Jan. 2017.

DELEUZE, G. Michel Foucault, filósofo. Barcelona: Gedisa, 1990.

DEUTSCHE WELLE. Israel aprova construção de 566 casas em Jerusalém Oriental. Disponível em: <http:// www.dw.com/pt-br/israel-aprova-construção-de-566casas-em-jerusalém-oriental/a-37230756>. Acesso em: 10 Jan. 2017.
FARSAKH, Leila. Darwish and the Meaning of Palestine. In: Human Architecture: Journal of the Sociology of Self-Knowledge, VII, n.7, 2009. p. 101-104.

FOUCAULT, Michel. Ditos e Escritos, v. III. Rio de Janeiro: Forense Universitária, 2009.

Power/Knowledge selected interviews and other writings. Nova lorque: Pantheon Books, 1977. GINZBURG, Carlo. Mitos, emblemas, sinais: morfologia e história. São Paulo: Companhia das Letras, 1989.

HAMOUDA, Sahar. Once Upon a time in Jerusalem. Reino Unido: Garnet, 2010.

HEGEL, G. W. Friedrich. A razão da história: Uma introdução geral à teoria da história. São Paulo: Centauro Editora, 2004.

HEIDEGGER, Martin. A caminho da linguagem. Petrópolis: Vozes, 2003.

LACAN, Jacques. Nomes-do-Pai. Rio de Janeiro: Jorge Zahar, 2005.

MASSEY, Doreen. Pelo espaço: uma nova política da espacialidade. Rio de Janeiro: Bertrand Brasil, 2008.

MBEMBE, Achille. Necropolítica. Santa Cruz de Tenerife: Melusina, 2006.

RANCIÈRE, Jacques. Estética e Política: A partilha do sensível. Porto: Dafne, 2010.
Politics, identification and subjectivation In: RAJCHMAN, John. The identity in question. Nova York: Routledge, 1995.

RICOEUR, Paul. Tempo e Narrativa: A Intriga e a Narrativa Histórica. v.1. São Paulo: WMF Martins Fontes, 2012.

\section{A memória, a história, o esquecimento.} Campinas: Unicamp, 2007.

Tempo e narrativa: O tempo narrado. v. 3. São Paulo: WMF Martins Fontes, 2010.

SACCO, Joe. Notas sobre Gaza. Tradução: Alexandre Boide. São Paulo: Companhia das Letras, 2010.

Reportagens. São Paulo: Companhia das Letras, 2016.

SAFATLE, Vladimir. $\mathbf{O}$ circuito dos afetos. São Paulo: Cosac Naify, 2015.

SAID, Edward W. Reflections on exile: and other literary and cultural essays. Londres: Granta Books, 2001.

Palestina existe. La lucha por la autodeterminación y la afirmación de la soberanía. In: Crítica y Emancipación. Ano VII No 14. Buenos Aires: CLACSO, 2015.

SHATZ, Adam. A Poet's Palestine as a Metaphor. The New York Times, 2001. Disponível em: <http://www. nytimes.com/2001/12/22/books/a-poet-s-palestine-asa-metaphor.html>. Acesso em: 20 dez. 2016. 
THE NEW YORK TIMES. A History of Anti-Arab Feeling. The New York Times, 1994. Disponível em <http:// www.nytimes.com/1994/02/26/world/l-a-history-ofanti-arab-feeling-299022.html>. Acesso em: 15 jan. 2017.

WILES, Rich. Remembering the Ibrahimi Mosque massacre. Aljazeera, 24 fev. 2014. Disponível em: $\quad<$ http://www.aljazeera.com/indepth/ inpictures/2014/02/remembering-ibrahimi-mosquema-2014223105915230233.html>. Acesso em: 15 jan. 2017.

VIVA PALESTINA. Declaração de independência. Palestina. Disponível em <http://www.vivapalestina. com.br/site/declaracao-de-independencia-palestina15-de-novembro-de-1988/>. Acesso em: 10 fev. 2017.

\section{Referências Audiovisuais}

AFKAR MEDIA. Under Siege. 2005. Formato Digital. Windows.

\section{Notas}

1 Uma versão deste trabalho foi apresentada ao Gru po de Trabalho Memória nas mídias do XXVI Encontro Anual da Compós, Faculdade Cásper Líbero, São Paulo - SP, 06 a 09 de junho de 2017. O trabalho foi realizado com apoio da CAPES e do programa Culturas Literárias do Global South, financiado pelo DAAD e Minstério da Cultura alemão.

2 Doutorando em Comunicação pela Universidade Federal Fluminense (2015). Mestre em Comunicação pela Universidade Federal de Pernambuco (2015). (Programa de Pós-Graduação da Universidade Federal Flumi- nense - Rua Tiradentes no 148, Ingá. Cep: 24210-510. Niterói - RJ). E-mail: diegoamaral000@gmail.com.

3 No original: " [...] for the loss of Eden, for the sorrows of dispossession and exile, for the declining power of the Arab world in its dealings with the West".

4 Label no original. Em uma tradução literal pode se referir à etiqueta, rótulo, etc.

5 Com a posse de Donald Trump foi aprovada por Israel a construção de mais 566 casas em Jerusalém oriental, território Palestino (Deutsche Welle, 2017)

6 Ver Foucault (2009).

7 No original: "el poder (que no es necesaria $\neg$ mente un poder estatal) hace referencia continua e invoca la excepcion, la urgencia y una nocion «ficcionalizada» del enemigo".

8 No original: "[...] is considered a savior of the Arab language."

9 No original: "In her absence I created her image: out of the earthly/ the hidden heavenly commences. I am here weighing/ the expanse with the Jahili odes ...and absence is the guide it is the guide".

10 No original: "Read if you can!/ Write if you can!/ He reads: water, water and water/ He writes a line on the sand: if it was not for the mirage/ I would have not been alive until now".
11 No original: "It's the traveler's good fortune that hope is despair's twin, or its improvised poem".

12 No original: "[...] we can't free ourselves of the historical moment."

13 No original: “El Estado colonial basa su pretension fundamental de soberania y de legitimidad de la autoridad en su propio relato de la historia y la identidad".

14 "Once upon a time in Jerusalem", no original.

15 Casa da família Fitani, em tradução livre do autor.

16 No original: "I have gone back in time and dragged out of the unwilling dephts of my mother, a tale worth telling. There is the exotic world of confined women, and harsh men. But there is also a dar standing in one of the most sacred spots of the earth. Within it are lived the ordinary lives of men, women and children, and the extraordinary lives of heroes and resistance fighters and space violated and ravaged by soldiers and thugs. There lie my roots, which go back in time immemorial. After all, the dar was standing there when Saladin won back Jerusalem. I bring the voice of the women of Jerusalem, who were silenced by tradition, by men, by occupation, and by all forms of oppression. I will capture the story of this pre-1948 Jerusalemite family before ir passes into oblivion".

17 No original: "Names, dates and details".

18 No original: "[And I, the] would-be historian, could only throw up my hands in despair at ever getting the 
names or dates that were forever slipping out of reach."

19 No original: "They had no Palestinian past, only a Lebanese present".

20 No original: "Ceding the 'West Bank' to the 'Palestinians ' would, therefore, not solve the problem which Rabbi Hertzberg raises: it would serve only to further jeopardize Israel's security and betray a Biblical trust". 